\title{
A three-layer supply chain integrated production-inventory model under permissible delay in payments in uncertain environments
}

\author{
Dipak Kumar Jana ${ }^{1 *}$, Kalipada Maity ${ }^{2}$ and Tapan Kumar Roy ${ }^{3}$
}

\author{
${ }^{*}$ Correspondence: \\ dipakjana@gmail.com \\ ${ }^{1}$ Department of Engineering \\ Science, Haldia Institute of \\ Technology, Haldia Purba Midna \\ Pur 721657, West Bengal, India \\ Full list of author information is \\ available at the end of the article
}

\begin{abstract}
In this paper, an integrated production-inventory model is presented for a supplier, manufacturer, and retailer supply chain under conditionally permissible delay in payments in uncertain environments. The supplier produces the item at a certain rate, which is a decision variable, and purchases the item to the manufacturer. The manufacturer has also purchased and produced the item in a finite rate. The manufacturer sells the product to the retailer and also gives the delay in payment to the retailer. The retailer purchases the item from the manufacture to sell it to the customers. Ideal costs of supplier, manufacturer, and retailer have been taken into account. An integrated model has been developed and solved analytically in crisp and uncertain environments, and finally, corresponding individual profits are calculated numerically and graphically.
\end{abstract}

Keywords: Production inventory system; Uncertain variables; Three-layer supplier chain; Delay in payment

\section{Introduction}

Supply chain management has taken a very important and critical role for any company in the increasing globalization and competition in the market. A supply chain model (SCM) is a network of suppliers, producers, distributors, and customers which synchronizes a series of interrelated business process in order to have (1) optimal procurement of raw materials from nature, (2) transportation of raw materials into a warehouse, (3) production of goods in the production center, and (4) distribution of these finished goods to retailers for sale to the customers. With a recent paradigm shift to the supply chain (SC), the ultimate success of a firm may depend on its ability to link supply chain members seamlessly.

One of the earliest efforts to create an integrated SCM has been developed by Oliver and Webber [1], Cohen and Baghanan [2], and Cachon and Zipkin [3]. They developed a production, distribution, and inventory (PDI) planning system that integrated three supply chain segments comprising supply, storage/location, and customer demand planning. The core of the PDI system was a network model and diagram that increased the decision

(c) 2013 Jana et al.; licensee Springer. This is an Open Access article distributed under the terms of the Creative Commons 
maker's insights into supply chain connectivity. The model however was confined to a single-period and single-objective problem. Viswanathan and Piplani [4] were concerned an integrated inventory model through common replenishment in the SC. Khouja [5] was the first to consider a three-stage supply chain with one or more firms at each stage. Agarwal et al. [6] have developed a dynamic balancing of inventory model in supply chain management. Rau et al. [7] developed an integrated SCM of a deteriorating item with shortages. Lee [8] added a new dimension to the single vendor-single buyer problem by setting the number of raw material shipments received by the vendor per cycle to be a decision variable. Ben-Daya et al. [9] have developed an integrated productioninventory model with raw material replenishment considerations in a three-layer supply chain. Sana [10] has integrated a production-inventory model of imperfect quality products in a three-layer supply chain. Recently, Pal et al. [11] have developed a three-layer supply chain model with production-inventory model for reworkable items. All of the abovementioned SCMs are considered with constant, known demand and production rates in a crisp environment.

Different types of uncertainty such as fuzziness, randomness, and roughness are common factors in SCM. In many cases, it is found that some inventory parameters involve fuzzy uncertainty. For example, inventory-related costs such as holding cost and setup cost, demand, and selling price depend on several factors such as bank interest, stock amount, and market situation which are uncertain in a fuzzy sense. To be more specific, inventory holding cost is sometimes represented by a fuzzy number, and it depends on the storage amount which may be imprecise and range within an interval due to several factors such as scarcity of storage space, market fluctuation, human estimation, and/or thought process. The following papers have been developed in these environments.

Wang and Shu [12] developed a fuzzy decision methodology that provides an alternative framework to handle SC uncertainties and to determine SC inventory strategies, while there is a lack of certainty in data or even a lack of available historical data. Fuzzy set theory is used to model SC uncertainty. A fuzzy SC model based on possibility theory is developed to evaluate SC performances. Based on the proposed fuzzy SC model, a genetic algorithm approach is developed to determine the order-up-to levels of stock-keeping units in the SC to minimize SC inventory cost subject to the restriction of fulfilling the target fill rate of the finished product. The proposed model allows decision makers to express their risk attitudes and to analyze the trade-off between customer service level and inventory investment in the SC, so that better SC inventory strategies can be made.

Das et al. [13] have presented a joint performance of an SC with two warehouse facilities in a fuzzy environment. A realistic two-warehouse and multi-collection-productioninventory model with constant/stock-dependent demand, defective production system, and fuzzy budget constraint has been formulated and solved in an SC context. Later Chen et al. [14] developed a multi-criteria fuzzy optimization for locating warehouses and distribution centers in a supply chain network.

Peidro et al. [15] developed a fuzzy linear programming model for tactical supply chain planning in a multi-echelon, multi-product, multi-level, multi-period supply chain network in a fuzzy environment. In this approach, the demand, process, and supply uncertainties are jointly considered. The aim is to centralize multi-node decisions 
simultaneously to achieve the best use of the available resources along the time horizon so that customer demands are met at a minimum cost. This proposal is tested using data from a real automobile SC. The fuzzy model provides the decision maker with alternative decision plans with different degrees of satisfaction.

Chu [16] developed the supply chain flexibility that has become increasingly important. This study thus builds a group decision-making structure model of flexibility in supply chain management development. Recently, Jana et al. [17] have developed a fuzzy simulation via contractive mapping genetic algorithm approach to an imprecise production-inventory model under volume flexibility. This study presents a framework to evaluate the supply chain flexibility that comprises two parts: (1) an evaluation hierarchy with flexibility dimensions and related metrics and (2) an evaluation scheme that uses a three-stage process to evaluate the supply chain flexibility. This study then proposes an algorithm to determine the degree of supply chain flexibility using a fuzzy linguistic approach. Evaluations of the degree of supply chain flexibility can identify the need to improve supply chain flexibility and identify specific dimensions of supply chain flexibility as the best directions for improvement. The results of this study are more objective and unbiased for two reasons. First, the results are generated by group decision-making with interactive consensus analysis. Second, the fuzzy linguistic approach used in this study has more advantages to preserve no loss of information than other methods. Additionally, this study presents an example using a case study to illustrate the availability of the proposed methods and compare it with other methods.

Kristianto et al. [18] developed an adaptive fuzzy control application to support a vendor-managed inventory (VMI). This paper also guides the management in allocating inventory by coordinating with suppliers and buyers to ensure minimum inventory levels across a supply chain. Adaptive fuzzy VMI control is the main contribution of this paper.

However, the uncertainty theory was developed by Liu [19], and it can be used to handle subjective imprecise quantity. Much research work has been done on the development of the uncertainty theory and related theoretical work. You [20] proved some convergence theorems of uncertain sequences. Liu [21] has defined uncertain process and Liu [22] has discussed uncertain theory. In this paper, we developed for the first time a three-layer supply chain model under delay in payment in an uncertain environment.

In the traditional economic order quantity (EOQ) model, it often assumed that the retailer must pay off as soon as the items are received. In fact, the supplier offers the retailer a delay period, known as trade credit period, in paying for the purchasing cost, which is a very common business practice. Suppliers often offer trade credit as a marketing strategy to increase sales and reduce on-hand stock level. Once a trade credit has been offered, the amount of the tied up retailer's capital in stock is reduced, and that leads to a reduction in the retailer's holding cost of finance. In addition, during the trade credit period, the retailer can accumulate revenues by selling items and by earning interests. As a matter of fact, retailers, especially of small businesses which tend to have a limited number of financing opportunities, rely on trade credit as a source of short-term funds. In this research field, Goyal [23] was the first to establish an EOQ model with a constant demand rate under the condition of permissible delay in payments. Khanra, Ghosh, and Chaudhuri [24] have developed an EOQ model for a deteriorating item with time-dependent quadratic demand under permissible delay in payment. Also, 
Maihami and Abadi [25] have established joint control of inventory and its pricing for non-instantaneously deteriorating items under permissible delay in payments and partial backlogging.

The proposed model considers a three-layer supply chain involving the supplier, manufacturer, and retailer who are responsible in transforming the raw materials into finished product and making them available to satisfy the customer's demand time. Inventory and production decisions are made at the supplier, manufacturer, and retailer levels in uncertain environments. The problem is to coordinate production and inventory decisions across the supply chain so that the total profit of the chain is maximized.

\section{Necessary knowledge about uncertain variables}

To better describe subjective imprecise quantity, Liu in [19] proposed an uncertain measure and further developed an uncertainty theory which is an axiomatic system of normality, monotonicity, self-duality, countable subadditivity and product measure.

Definition 1. Let $\Gamma$ be a non-empty set and $L$ be a $\sigma$ algebra over $\Gamma$. Each element $\Lambda \in L$ is called an event. A set function $\mathcal{M}\{\Lambda\}$ is called an uncertain measure if it satisfies the following four axioms of Liu [19]:

Axiom 1. (Normality) $\mathcal{M}\{\Lambda\}=1$

Axiom 2. (Monotonicity) $\mathcal{M}\{\Lambda\}+\mathcal{M}\left\{\Lambda^{C}\right\}=1$, for any event $\Lambda$

Axiom 3. (Countable subadditivity) For every countable sequence of events $\Lambda_{1}, \Lambda_{2}, \ldots$, we have

$$
\mathcal{M}\left\{\sum_{i=1}^{\infty} \Lambda_{i}\right\} \leq \sum_{i=1}^{\infty} \mathcal{M}\left\{\Lambda_{i}\right\} .
$$

Definition 2. (Liu [19]) The uncertainty distribution $\Phi: R \rightarrow[0,1]$ of an uncertain variable $\xi$ is defined by

$$
\Phi(t)=\mathcal{M}\{\xi \leq t\} .
$$

Definition 3. (Liu [19]) Let $\xi$ be an uncertain variable. Then the expected value of $\xi$ is defined by

$$
E[\xi]=\int_{0}^{\infty} \mathcal{M}\{\xi \geq r\} d r-\int_{-\infty}^{0} \mathcal{M}\{\xi \leq r\} d r,
$$

provided that at least one of the two integrals is finite.

Theorem 1. (Liu [26]) Let $\xi$ be an uncertain variable with uncertainty distribution $\Phi$. If the expected value exists, then $E[\xi]=\int_{0}^{1} \Phi^{-1}(\alpha) d \alpha$.

Lemma 1. Let $\xi \sim \mathcal{L}(a, b, c)$ be a zigzag uncertain variable. Then its inverse uncertainty distribution $\Phi^{-1}(\alpha)=\frac{1}{2}[(1-\alpha) a+b+\alpha c]$, and it can be expressed as

$$
E[\xi]=\int_{0}^{1} \frac{1}{2}[(1-\alpha) a+b+\alpha c] d \alpha=\frac{a+2 b+c}{4} .
$$


Theorem 2. (Liu [26]) Let $\xi_{1}, \xi_{2}, \ldots, \xi_{n}$ be independent uncertain variables with uncertainty distributions $\phi_{1}, \phi_{2}, \ldots, \phi_{n}$, respectively. If $f$ is a strictly increasing function, then $\xi=f\left(\xi_{1}, \xi_{2}, \ldots, \xi_{n}\right)$ is an uncertain variable with inverse uncertainty distribution

$$
\Phi^{-1}(\alpha)=f\left(\Phi_{1}^{-1}(\alpha), \Phi_{2}^{-1}(\alpha), \ldots, \Phi_{n}^{-1}(\alpha)\right) .
$$

Theorem 3. (Liu [26]) Let $\xi_{1}$ and $\xi_{2}$ be independent uncertain variables with finite expected values. Then for any real numbers $a_{1}$ and $a_{2}$, we have

$$
E\left[a_{1} \xi+a_{2} \eta\right]=a_{1} E[\xi]+a_{2} E[\eta] .
$$

\section{Assumptions and notations}

\section{Assumptions}

The following assumptions are considered to develop the model:

(i) Models are developed for single item product.

(ii) Lead time is negligible.

(iii) Joint effect of supplier, manufacturer, retailer is consider in a supply chain management.

(iv) Supplier produced the item with constant rate unit per unit time, which is a decision variable.

(v) Total production rate of manufacturer is equal to the demand rate of manufacturer.

(vi) The manufacturer give the opportunity to the retailer conditionally permissible delay in payment.

(vii) Idle cost of suppliers, manufacturer and retailer are also assumed.

\section{Notations}

The following notations are considered to develop the model:

- $p_{s}=$ production rate for the suppliers, which is a decision variable.

- $p_{m}=$ demand rate or production rate for the manufacturer.

- $D_{r}=$ constant demand rate for the retailer.

- $D_{c}=$ constant demand rate of customer.

- $C_{s}=$ purchase cost of unit item for suppliers.

- $C_{m}=$ selling price of unit item for suppliers which is also the purchase cost for manufacturer.

- $C_{r}=$ selling price of unit item for manufacturer which is also the purchase cost for retailers.

- $C_{r_{1}}=$ selling price for retailers.

- $t_{s}=$ production time for supplers

- $T_{s}=$ cycle length for the suppliers.

- $T_{r}=$ time duration where order is supplied by the manufacturer, by retailer's cycle length.

- $T^{\prime}=$ last cycle length of the retailer.

- $T=$ total time for the integrated model.

- $h_{s}=$ holding cost per unit per unit time for suppliers.

- $h_{m}=$ holding cost per unit per unit time for manufacturer.

- $h_{r}=$ holding cost per unit per unit time for retailers. 
- $A_{s}=$ ordering cost for suppliers.

- $A_{m}=$ ordering cost for manufacturer.

- $h_{r}=$ ordering cost for retailers.

- $\operatorname{id}_{s}, \widetilde{\mathrm{d}}_{s}=$ idle cost per unit time for suppliers in crisp and uncertain environments, respectively.

- $\operatorname{id}_{m}, \widetilde{\mathrm{id}_{m}}=$ idle cost per unit time for manufacturer in crisp and uncertain environments, respectively.

- $\mathrm{id}_{r}, \widetilde{\mathrm{d}}_{r}=$ idle cost per unit time for retailers in crisp and uncertain environments, respectively.

- $\mathrm{n}=$ number of cycle for retailers.

- $r=$ number of cycles where manufacturer stops production.

- $M=$ retailer's trade credit period offered by the manufacturer to the retailers in years, which is the fraction of the years.

- $I_{p}=$ interest payable to the manufacturer by the retailers.

- $I_{e}, \widetilde{I_{e}}=$ interest earned by the retailers in crisp and uncertain environments, respectively.

- $\mathrm{ATP}=$ average total profit for the integrated models.

- $P_{m}^{*}=$ optimum value of $P_{m}$ for integrated models.

- $\mathrm{ATP}^{*}=$ optimum value of average total profit for the integrated models.

\section{Model description and diagrammatic representation}

The integrated inventory model (Figure 1) starts when $t=0$ and stock is zero. At that time, the suppliers start their production with the rate $p_{s}$ unit per unit time and purchase at the rate $p_{m}$ unit per unit time to the manufacturer. When $t=t_{s}$, suppliers stop their production, and at $t=T_{s}$, the inventory level of suppliers become zero. The total time of the integrated model is $T$, so the idle time for suppliers is $T-T_{S}$. Similarly, the

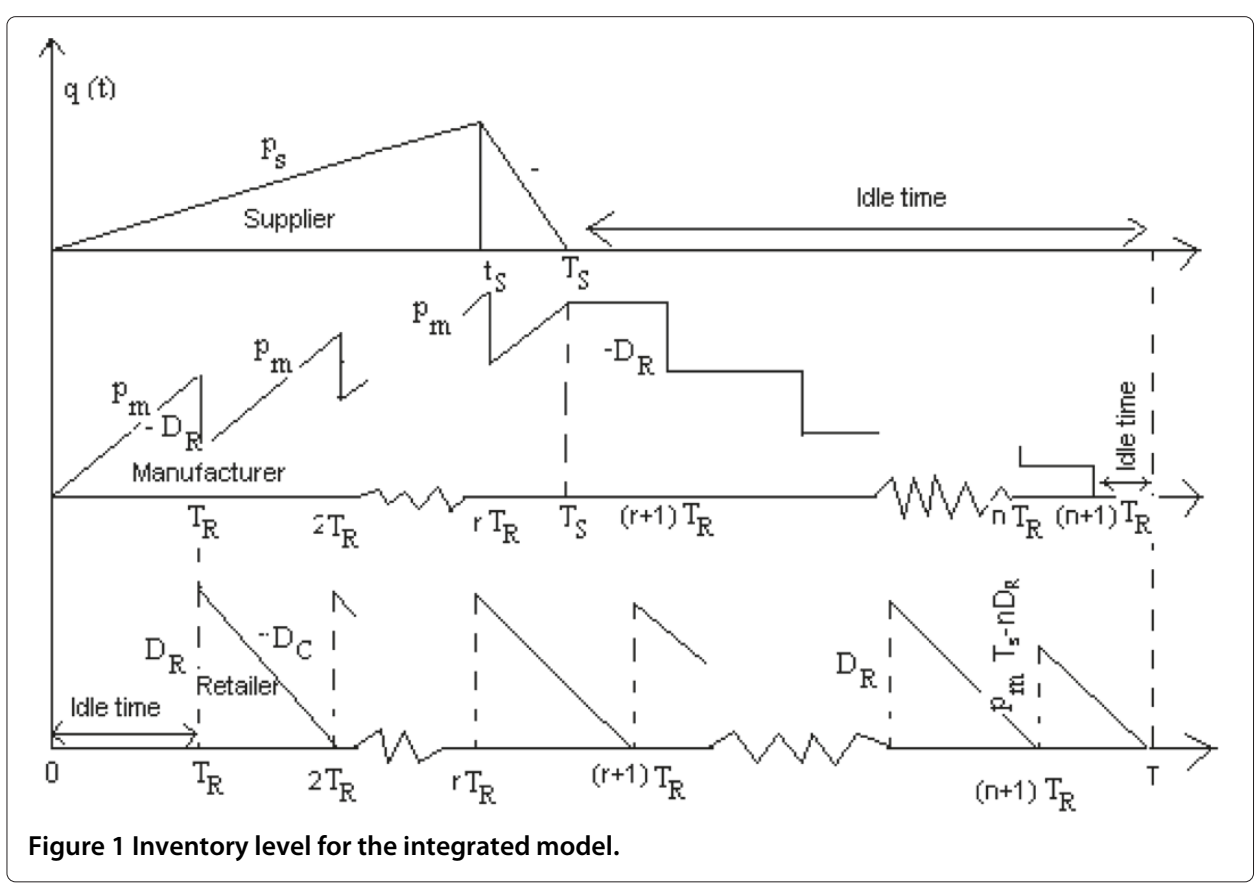


manufacturers start their production at the same time $t=0$ with the production rate $p_{m}$ unit per unit time and purchase this production $D_{r}$ unit to the retailer in the time gap $T_{R}$, which is the bulk pattern. At time $t=T_{S}\left(=\left[\frac{T_{S}}{T_{R}}\right]\right)$, manufacturers stop their production, and at $t=(n+1) T_{R}\left(n=\left[\frac{p_{m} T_{s}}{D_{r}}\right]\right)$, the stock of manufacturer is zero. Thus, idle period for the manufacturer is $T-(n+1) T_{r}$. Retailers start selling this product to the customers at time $t=T_{r}$ and end selling at $T=(n+1) T_{r}+\frac{p_{m} T_{s}-n D_{r}}{D_{c}}$. The idle period for retailers is $T_{r}$.

\section{Mathematical formulation of the model}

\section{Formulation of suppliers' individual average profit}

Differential equation for the supplier in Figure 2 in $[0, T]$ is given by

$$
\frac{d q_{s}}{d t}=\left\{\begin{array}{lrl}
p_{s}-p_{m}, & 0 \leq t \leq t_{s} \\
-p_{m}, & t_{s} \leq t \leq T_{s}, \\
0, & T_{s} \leq t \leq T
\end{array}\right.
$$

with boundary conditions $q_{s}(t)=0$ and $t=0, T_{s}$. Solving the differential equation with the boundary condition, we have

$$
\begin{aligned}
q_{s}(t)= \begin{cases}\left(P_{s}-P_{m}\right) t, & 0 \leq t \leq t_{s} \\
P_{m}\left(T_{s}-t\right), & t_{s}<t \leq T_{s} \\
0, & T_{s}<t \leq T\end{cases} \\
H_{s}=\text { Holding cost of supplier. } \\
\quad=h_{s}\left[\int_{0}^{t_{s}}\left(p_{s}-p_{m}\right) t d t+\int_{t_{s}}^{T_{s}} p_{m}\left(T_{s}-t\right) d t\right] \\
\quad=h_{s}\left[\frac{p_{s} t_{s}^{2}}{p_{m}}-p_{s} t_{s}^{2}\right] .
\end{aligned}
$$

The total idle cost $=\operatorname{id}_{s}\left[T_{R+P_{s}} t_{s}\left(\frac{1}{D_{c}}-\frac{1}{p_{m}}\right)\right]$, purchase cost $=c_{s} p_{m} T_{s}$, selling price $=$ $c_{m} p_{m} T_{s}$, and ordering cost $=A_{s}$.

APS $=$ Average profit for supplier.

$=\frac{1}{T}$ [revenue from sale-purchase cost-holding cost-idle cost-ordering cost.]

$=\frac{1}{T}\left[\left(c_{m}-c_{s}\right) p_{s} t_{s}-h_{s}\left(\frac{p_{s}^{2} t_{s}^{2}}{p_{m}}-p_{s} t_{s}^{2}\right)-\operatorname{id}_{s}\left(T_{R}+p_{s} t_{s}\left(\frac{1}{D_{c}}-\frac{1}{p_{m}}\right)\right)-A_{s}\right]$.

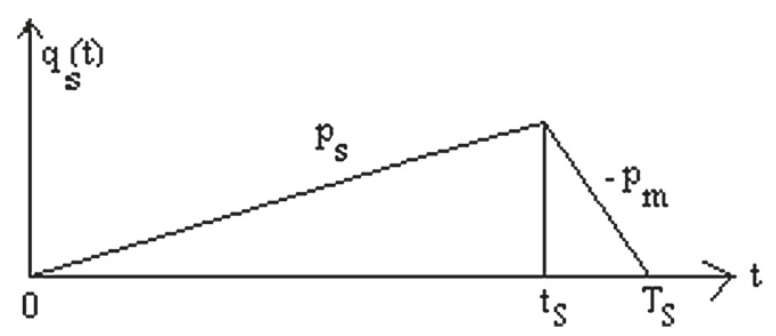

Figure 2 Inventory level of supplier. 
Formulation of manufacturer individual average profit

Inventory level of manufacturer in Figure 3 in $[0, T]$ is given by

$$
q_{m}(t)= \begin{cases}p_{m} t, & 0 \leq t \leq T_{R} \\ p_{m} t-i D_{R}, & i T_{R}<t \leq(i+1) T_{R} \quad i=1,2, \ldots,(r-1) \\ p_{m} t-r D_{R}, & r T_{R}<t \leq T_{s} \\ p_{m} T_{s}-r D_{R}, & T_{s}<t \leq(r+1) T_{R} \\ p_{m} T_{s}-i D_{R}, & i T_{R}<t \leq(i+1) T_{R} \quad i=r+1, r+2, \ldots, n-1 \\ p_{m} T_{s}-n D_{R}, & n T_{R}<t \leq(n+1) T_{R} \\ 0, & (n+1) T_{R} \leq t \leq T\end{cases}
$$

with boundary conditions $q_{m}(0)=0$ and $q_{m}\left(i T_{R}+0\right)=q_{m}\left(i T_{R}\right)-D_{R}$.

$H_{m}=$ Holding cost for manufacturer.

$$
\begin{aligned}
= & h_{m}\left[\int_{0}^{T_{R}} p_{m} t d t+\sum_{1}^{r-1} \int_{i T_{R}}^{(i+1) T_{R}}\left(p_{m} t-i D_{R}\right) d t+\int_{r T_{R}}^{\left(T_{s}\right.}\left(p_{m} t-r D_{R}\right) d t\right. \\
& \left.+\int_{T_{s}}^{(r+1) T_{R}}\left(p_{m} T_{s}-r D_{R}\right) d t+\sum_{r+1}^{n-1} \int_{i T_{R}}^{(i+1) T_{R}}\left(p_{m} T_{s}-i D_{R}\right) d t+\int_{n T_{R}}^{(n+1) T_{R}}\left(p_{m} T_{s}-n D_{R}\right) d t\right] \\
= & h_{m}\left[n p_{m} T_{s} T_{R}-\frac{n^{2}+n-2 r-2}{2} T_{R} D_{R}-\frac{p_{s}^{2} t_{s}^{2}}{2 p_{m}}\right] .
\end{aligned}
$$

The total idle cost $=\operatorname{id}_{m}\left[\frac{p_{m} T_{m}-n D_{R}}{D_{c}}\right]$, purchase cost $=c_{m} p_{m} T_{s}$, selling price $=c_{r} p_{m} T_{s}$, and ordering cost $=A_{m}$.

Case 1. (When $M \leq T^{\prime} \leq T_{R}$ )

$$
\begin{aligned}
I_{e m}=I_{p r}= & \text { Amount of interest earned by the manufacturer in }[0, T] \text { from retailer. } \\
= & \text { Amount of interest paid by the retailer to the manufacturer in }[0, T] \\
= & c_{r} I_{p}\left[n \int_{M}^{T_{R}}\left(D_{R}-D_{c} t\right) d t+\int_{M}^{T^{\prime}}\left(p_{m} T_{s}-n D_{R}-D_{c} t\right) d t\right] \\
= & \frac{n c_{r} I_{p}}{2}\left[T_{R} D_{R}+D_{c} M^{2}-2 M D_{R}\right]+c_{r} I_{p}\left[\left(\frac{\left(p_{m} T_{s}-n D_{R}\right)^{2}}{2 D_{c}}\right.\right. \\
& \left.+\left(p_{m} T_{s}-n D_{R}\right) M+\frac{D_{c} M^{2}}{2}\right]
\end{aligned}
$$

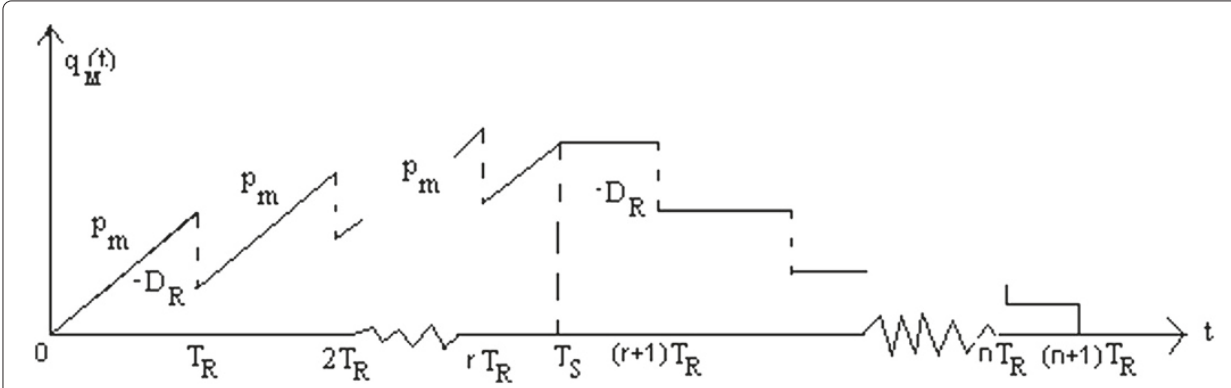

Figure 3 Inventory level of manufacturer. 
$\mathrm{APM}_{1}=$ Average profit of manufacturer.

$=\frac{1}{T}[$ revenue from sale-purchase cost-holding cost-idle cost

+ earned interest-ordering cost.]

$$
\begin{aligned}
= & \frac{1}{T}\left[\left(c_{r}-c_{m}\right) p_{m} T_{s}-h_{m}\left(n p_{m} T_{s} T_{R}-\frac{n^{2}+n-2 r-2}{2} T_{R} D_{R}-\frac{p_{s}^{2} t_{s}^{2}}{2 p_{m}}\right)\right. \\
& -\operatorname{id}_{m}\left(\frac{p_{m} T_{m}-n D_{R}}{D_{c}}\right)+\frac{n c_{r} I_{p}}{2}\left[T_{R} D_{R}+D_{c} M^{2}-2 M D_{R}\right] \\
& \left.+c_{r} I_{p}\left(\frac{\left(p_{m} T_{s}-n D_{R}\right)^{2}}{2 D_{c}}+\left(p_{m} T_{s}-n D_{R}\right) M+\frac{D_{c} M^{2}}{2}\right)-A_{m}\right]
\end{aligned}
$$

Case 2. (When $T^{\prime} \leq M \leq T_{R}$ )

$I_{e m}=I_{p r}=$ Amount of interest earned by the manufacturer in $[0, T]$ from retailer.

$=$ Amount of interest paid by the retailer to the manufacturer in $[0, T$. $]$

$$
\begin{aligned}
= & c_{r} I_{p}\left[n \int_{M}^{T_{R}}\left(D_{R}-D_{c} t\right) d t+\int_{M}^{T^{\prime}}\left(p_{m} T_{s}-n D_{R}-D_{c} t\right) d t\right] \\
= & \frac{n c_{r} I_{p}}{2}\left[T_{R} D_{R}+D_{c} M^{2}-2 M D_{R}\right]+c_{r} I_{p}\left[\left(\frac{\left(p_{m} T_{s}-n D_{R}\right)^{2}}{2 D_{c}}\right.\right. \\
& \left.+\left(p_{m} T_{s}-n D_{R}\right) M+\frac{D_{c} M^{2}}{2}\right]
\end{aligned}
$$

$\mathrm{APR}_{2}=$ Average profit of retailer.

$=\frac{1}{T}[$ revenue from sale-purchase cost-holding cost

+ earned interest-payable interest-idle cost-ordering cost].

$$
\begin{aligned}
= & \frac{1}{T}\left[\left(c_{r_{1}}-c_{r}\right) p_{m} T_{s}-\frac{h_{r}}{2}\left(\frac{p_{m}^{2} T_{s}^{2}}{D_{c}}-2 n p_{m} T_{s} T_{R}-(2 n+1) T_{R} D_{R}\right)\right. \\
& +\frac{n c_{r_{1}} i_{e} D_{c} M^{2}}{2}+\frac{c_{r_{1}} i_{e}}{2}\left(p_{m} T_{s}-n D_{R}\right)\left(2 M-T^{\prime}\right) \\
& \left.-\frac{n c_{r} I_{p}}{2}\left[T_{R} D_{R}+D_{c} M^{2}-2 M D_{R}\right]-\mathrm{id}_{r} T_{R}-A_{r}\right]
\end{aligned}
$$

\section{Formulation of retailer individual average profit}

Inventory level of retailer in Figure 4 in $[0, T]$ is given by

$$
q_{r}(t)= \begin{cases}D_{c} t, & i T_{R} \leq t \leq(i+1) T_{R} \\ p_{m} T_{s}-n D_{r}-D_{c} t, & (n+1) T_{R} \leq t \leq T\end{cases}
$$

with boundary conditions $q_{r}\left((n+1) T_{R}\right)=0$ and $q_{r}(T)=0$.

$$
\begin{aligned}
H_{r} & =\text { Holding cost of retailer. } \\
& =n h_{r}\left[\int_{0}^{T_{R}}\left(D_{R}-D_{c} t\right) d t+\int_{0}^{T^{\prime}}\left(p_{m} T_{s}-n D_{R}-D_{c} t\right) d t\right] \\
& =\frac{h_{r}}{2}\left[\frac{p_{m}^{2} T_{s}^{2}}{D_{c}}-2 n p_{m} T_{s} T_{R}-(2 n+1) T_{R} D_{R}\right] .
\end{aligned}
$$




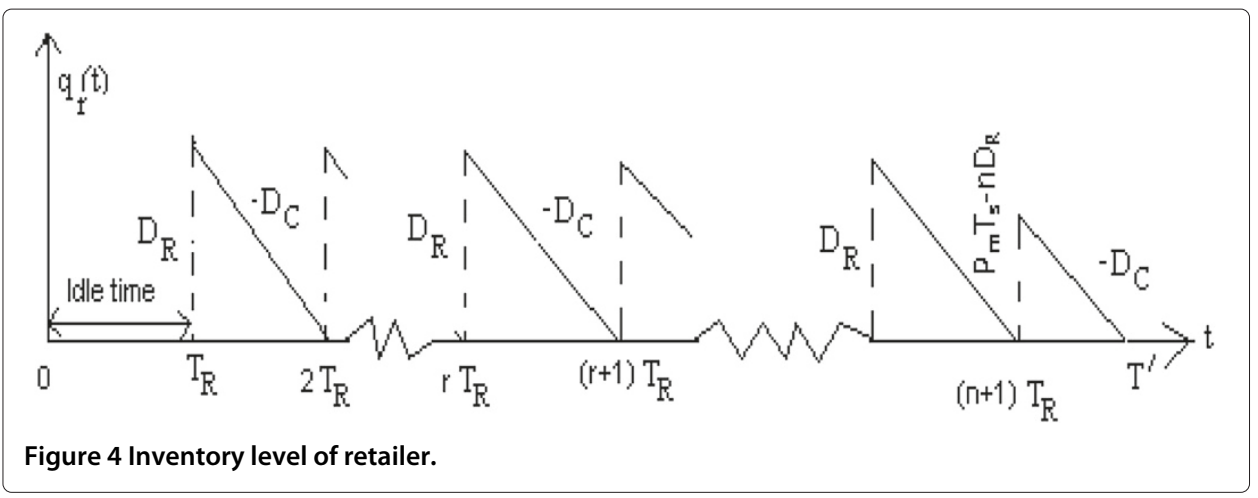

The total idle cost $=\mathrm{id}_{r} T_{R}$, purchase cost $=c_{r} p_{m} T_{s}$, selling price $=c_{r 1} p_{m} T_{s}$, and ordering cost $=A_{r}$.

Case 1. (When $M \leq T^{\prime} \leq T_{R}$ )

Interest earned by the retailers for $(n+1)$ cycle is given by

$$
\begin{aligned}
I_{e r}= & \text { Amount of interest earned by the retailer from the bank in }(n+1) \text { cycle. } \\
= & (n+1) c_{r_{1}} i_{e}\left[\int_{0}^{M}(M-t) D_{c} d t\right] \\
= & \frac{(n+1) c_{r_{1}} i_{e} D_{c} M^{2}}{2}, \\
I_{p r}= & \text { Amount of interest paid by the retailer to the manufacturer in }[0, T] . \\
= & c_{r} I_{p}\left[n \int_{M}^{T_{R}}\left(D_{R}-D_{c} t\right) d t+\int_{M}^{T^{\prime}}\left(p_{m} T_{s}-n D_{R}-D_{c} t\right) d t\right] \\
= & n c_{r} I_{p}\left[\frac{T_{R} D_{R}+D_{c} M^{2}-2 M D_{R}}{2}\right]+c_{r} I_{p}\left[\frac{\left(p_{m} T_{s}-n D_{R}\right)^{2}}{2 D_{c}}\right. \\
& \left.+\left(p_{m} T_{s}-n D_{R}\right) M+\frac{D_{c} M^{2}}{2}\right],
\end{aligned}
$$

$$
\begin{aligned}
\mathrm{APR}_{1}= & \text { Average profit for retailer. } \\
= & \frac{1}{T} \text { [revenue from sale-purchase cost-holding cost } \\
& + \text { earned interest-payable interest-idle cost-ordering cost.] } \\
= & \frac{1}{T}\left[c_{r_{1}} p_{m} T_{s}-c_{r} p_{m} T_{s}-\frac{h_{r}}{2}\left(\frac{p_{m}^{2} T_{s}^{2}}{D_{c}}-2 n p_{m} T_{s} T_{R}-(2 n+1) T_{R} D_{R}\right)\right. \\
& +\frac{(n+1) c_{r_{1}} i_{e} D_{c} M^{2}}{2}-\frac{n c_{r} I_{p}}{2}\left[T_{R} D_{R}+D_{c} M^{2}-2 M D_{R}\right]-\mathrm{id}_{r} T_{R}-A_{r} \\
& \left.+\left(p_{m} T_{s}-n D_{R}\right) M+\frac{D_{c} M^{2}}{2}\right)-c_{r} I_{p}\left(\frac{\left(p_{m} T_{s}-n D_{R}\right)^{2}}{2 D_{c}}\right]
\end{aligned}
$$

Case 2. (When $T^{\prime} \leq M \leq T_{R}$ )

Interest earned by the retailers for $(n+1)$ cycle is given by 


$$
\begin{aligned}
I_{r e} & =\text { Retailers' earned interest. } \\
& =c_{r_{1}} i_{e}\left[n \int_{0}^{M}(M-t) D_{c} d t+\int_{0}^{T^{\prime}}\left(T^{\prime}-t\right) D_{c} d t+\left(M-T^{\prime}\right)\left(p_{m} T_{s}-n D_{R}\right)\right] \\
& =\frac{n c_{r_{1}} i_{e} D_{c} M^{2}}{2}+\frac{c_{r_{1}} i_{e}}{2}\left(p_{m} T_{s}-n D_{R}\right)\left(2 M-T^{\prime}\right)
\end{aligned}
$$

Interest payable by the retailers for the first $n$ cycle is given by

$$
\begin{aligned}
I_{r p}= & \text { Retailers' payable interest. } \\
= & c_{r} I_{p}\left[n \int_{M}^{T_{R}}\left(D_{R}-D_{c} t\right) d t\right] \\
= & \frac{n c_{r} I_{p}}{2}\left[T_{R} D_{R}+D_{c} M^{2}-2 M D_{R}\right] \\
\mathrm{APR}_{2}= & \text { Average profit for retailer. } \\
= & \frac{1}{T}[\text { revenue from sale-purchase cost-holding cost } \\
& + \text { earned interest-payable interest-idle cost-ordering cost }] \\
= & \frac{1}{T}\left[\left(c_{r_{1}}-c_{r}\right) p_{m} T_{s}-\frac{h_{r}}{2}\left(\frac{p_{m}^{2} T_{s}^{2}}{D_{c}}-2 n p_{m} T_{s} T_{R}-(2 n+1) T_{R} D_{R}\right)\right. \\
& +\frac{n c_{r_{1}} i_{e} D_{c} M^{2}}{2}+\frac{c_{r_{1}} i_{e}}{2}\left(p_{m} T_{s}-n D_{R}\right)\left(2 M-T^{\prime}\right) \\
& \left.\quad-\frac{n c_{r} I_{p}}{2}\left[T_{R} D_{R}+D_{c} M^{2}-2 M D_{R}\right]-\mathrm{id}_{r} T_{R}-A_{r}\right]
\end{aligned}
$$

\section{Crisp environment}

Case 1. $\left(M \leq T^{\prime} \leq T_{R}\right)$

$\mathrm{ATP}_{1}=$ Total average profit for integrated model.

$$
\begin{aligned}
= & \mathrm{APS}+\mathrm{APM}_{1}+\mathrm{APR}_{1} \\
= & \frac{D_{c}}{p_{m} T_{s}}+D_{R}\left[\left(c_{m}-c_{s}\right) p_{m} T_{s}-h_{s}\left(\frac{p_{s} t_{s}^{2}}{p_{m}}-p_{s} t_{s}^{2}\right)-\mathrm{id}_{s}\left(T_{R}+p_{s} t_{s} \frac{1}{D_{c}}-\frac{1}{p_{m}}\right)-A_{s}\right. \\
& +\left(c_{r}-c_{m}\right) p_{m} T_{s}-h_{m}\left(n p_{m} T_{s} T_{R}-\frac{n^{2}+n-2 r-2}{2} T_{R} D_{R}-\frac{p_{s}^{2} t_{s}^{2}}{2 p_{m}}\right) \\
& -\mathrm{id}_{m}\left(\frac{p_{m} T_{m}-n D_{R}}{D_{c}}\right) \\
& -A_{m}+\left(c_{r_{1}}-c_{r}\right) p_{m} T_{s}-\frac{h_{r}}{2}\left(\frac{p_{m}^{2} T_{s}^{2}}{D_{c}}-2 n p_{m} T_{s} T_{R}-(2 n+1) T_{R} D_{R}\right) \\
& \left.+\frac{(n+1) c_{r_{1}} I_{e} D_{c} M^{2}}{2}-\mathrm{id}_{r} T_{R}-A_{r}\right] \\
= & \frac{D_{c}}{p_{m} T_{s}+D_{R}}\left[A p_{s}^{2} t_{s}^{2}-B p_{s} t_{s}+E\right],
\end{aligned}
$$

where $P_{m} T_{s}=P_{s} t_{s}$,

$$
\begin{aligned}
& A=\frac{h_{m}-h_{s}}{2 p_{m}}-\frac{h_{r}}{2 D_{c}} \\
& B=\left(c_{r_{1}}-c_{s}\right)+n\left(h_{r}-h_{m}\right) T_{R}-\frac{\mathrm{id}_{m}+\mathrm{id}_{s}}{D_{c}}
\end{aligned}
$$


and

$$
\begin{aligned}
& \begin{array}{l}
E= \\
\quad\left[h_{m} \frac{n^{2}+n-2 r-2}{2}+h_{r} \frac{2 n+1}{2}\right] T_{R} D_{R}+\frac{(n+1) c_{r_{1}} I_{e} D_{c} M^{2}}{2} \\
\quad+\left(n \mathrm{id}_{m}-\mathrm{id}_{s}-\mathrm{id}_{r}\right) T_{R}+\mathrm{id}_{s} T_{s}-\left(A_{s}+A_{m}+A_{r}\right)
\end{array} \\
& \quad \Rightarrow p_{s}=\frac{2 D_{R}-B \pm \sqrt{\left(2 t_{s}-A\right)^{2}-4\left(2 t_{s}-A\right)\left(E-B D_{R}\right)}}{2\left(2 t_{s}-A\right)} \\
& \frac{d^{2}}{d p_{s}}\left(\mathrm{ATP}_{1}\right)=0 \\
& \frac{d^{2}}{d p_{s}^{2}}\left(\mathrm{ATP}_{1}\right)<0, \quad \text { if } 2 A p_{s}+B<4 p_{s} t_{s}+B t_{s}+2 D_{R} .
\end{aligned}
$$

Therefore, $\mathrm{ATP}_{1}$ is concave if

$$
2 A p_{s}+B<4 p_{s} t_{s}+B t_{s}+2 D_{R} \text {. }
$$

Case 2. $\left(T^{\prime} \leq M \leq T_{R}\right)$

$\mathrm{ATP}_{2}=$ Total average profit for integrated model.

$$
\begin{aligned}
= & \mathrm{APS}+\mathrm{APM}_{1}+\mathrm{APR}_{1} \\
= & \frac{D_{c}}{p_{m} T_{s}+D_{R}}\left[\left(c_{m}-c_{s}\right) p_{m} T_{s}-h_{s}\left(\frac{p_{s} t_{s}^{2}}{p_{m}}-p_{s} t_{s}^{2}\right)-\mathrm{id}_{s}\left(T_{R}+p_{s} t_{s} \frac{1}{D_{c}}-\frac{1}{p_{m}}\right)-A_{s}\right. \\
& +\left(c_{r}-c_{m}\right) p_{m} T_{s}-h_{m}\left(n p_{m} T_{s} T_{R}-\frac{n^{2}+n-2 r-2}{2} T_{R} D_{R}-\frac{p_{s}^{2} t_{s}^{2}}{2 p_{m}}\right) \\
& -\mathrm{id}_{m}\left(\frac{p_{m} T_{m}-n D_{R}}{D_{c}}\right) \\
& -A_{m}+\left(c_{r 1}-c_{r}\right) p_{m} T_{s}-\frac{h_{r}}{2}\left(\frac{p_{m}^{2} T_{s}^{2}}{D_{c}}-2 n p_{m} T_{s} T_{R}-(2 n+1) T_{R} D_{R}\right) \\
& \left.+\frac{n c_{r_{1}} I_{e} D_{c} M^{2}}{2}+\frac{c_{r_{1}} I_{e}}{2}\left(p_{m} T_{s}-n D_{R}\right)(2 M-T)-\mathrm{id}_{r} T_{R}-A_{r}\right] \\
= & \frac{D_{c}}{p_{m} T_{s}+D_{R}}\left[A p_{s}^{2} t_{s}^{2}-B p_{s} t_{s}+F\right]
\end{aligned}
$$

where $A$ and $B$ are given in (16) and (17), respectively and

$$
\begin{aligned}
& F= {\left[h_{m} \frac{n^{2}+n-2 r-2}{2}+h_{r} \frac{2 n+1}{2}\right] T_{R} D_{R}+\frac{(n+1) c_{r_{1}} I_{e} D_{c} M^{2}}{2} } \\
&+\left(n \mathrm{id}_{m}-\mathrm{id}_{s}-\mathrm{id}_{r}\right) T_{R}+\mathrm{id}_{s} T_{s}-\left(A_{s}+A_{m}+A_{r}\right) \\
& \frac{d}{d p_{s}}\left(\mathrm{ATP}_{2}\right)= 0 \\
& \Rightarrow p_{s}= \frac{2 D_{R}-B \pm \sqrt{\left(2 t_{s}-A\right)^{2}-4\left(2 t_{s}-A\right)\left(F-B D_{R}\right)}}{2\left(2 t_{s}-A\right)} \\
& \frac{d^{2}}{d p_{s}^{2}}\left(\mathrm{ATP}_{1}\right)<0, \quad \text { if } 2 A p_{s}+B<4 p_{s} t_{s}+B t_{s}+2 D_{R} .
\end{aligned}
$$

Therefore, $\mathrm{ATP}_{1}$ is concave if 


$$
2 A p_{s}+B<4 p_{s} t_{s}+B t_{s}+2 D_{R} \text {. }
$$

\section{Proposed inventory model in uncertain environment}

Let us consider $\widetilde{i d}_{s}, \widetilde{i d}_{r}, \tilde{i d}_{m}$, and $\widetilde{I}_{r e}$ as zigzag uncertain variables where i $\tilde{\mathrm{d}}_{s}=$ $L\left(\mathrm{id}_{s_{1}}, \mathrm{id}_{s_{2}}, \mathrm{id}_{s_{3}}\right)$, $\tilde{\mathrm{d}}_{r}=L\left(\mathrm{id}_{r_{1}}, \mathrm{id}_{m_{2}}, \mathrm{id}_{r_{3}}\right)$, $\mathrm{id}_{m}=L\left(\mathrm{id}_{m_{1}}, \mathrm{id}_{m_{2}}, \mathrm{id}_{m_{3}}\right)$, and $\tilde{I_{r e}}=$ $L\left(I_{r_{1}}, I_{r e_{2}}, I_{r e_{3}}\right)$. Then, the objective is reduce to the following:

- For Case $1\left(M \leq T^{\prime} \leq T_{R}\right)$

$$
\begin{aligned}
\mathrm{A} \tilde{\mathrm{TP}}{ }_{1}= & \frac{D_{c}}{p_{m} T_{s}+D_{R}}\left[0\left(c_{m}-c_{s}\right) p_{m} T_{s}-h_{s}\left(\frac{p_{s} t_{s}^{2}}{p_{m}}-p_{s} t_{s}^{2}\right)-\tilde{i d}_{s}\left(T_{R}+p_{s} t_{s}\left(\frac{1}{D_{c}}-\frac{1}{p_{m}}\right)\right)\right. \\
& -A_{s}+\left(c_{r}-c_{m}\right) p_{m} T_{s}-h_{m}\left(n p_{m} T_{s} T_{R}-\frac{n^{2}+n-2 r-2}{2} T_{R} D_{R}-\frac{p_{s}^{2} t_{s}^{2}}{2 p_{m}}\right) \\
& -A_{m}+\left(c_{r_{1}}-c_{r}\right) p_{m} T_{s}-\frac{h_{r}}{2}\left(\frac{p_{m}^{2} T_{s}^{2}}{D_{c}}-2 n p_{m} T_{s} T_{R}-(2 n+1) T_{R} D_{R}\right) \\
& \left.-\tilde{i d}_{m}\left(\frac{p_{m} T_{m}-n D_{R}}{D_{c}}\right)+\frac{(n+1) c_{r_{1}} \tilde{I}_{r e} D_{c} M^{2}}{2}-\tilde{i d}_{r} T_{R}-A_{r}\right] .
\end{aligned}
$$

- For Case $2\left(T^{\prime} \leq M \leq T_{R}\right)$

$$
\begin{aligned}
\mathrm{AT}_{2}= & \frac{D_{c}}{p_{m} T_{s}+D_{R}}\left[\left(c_{m}-c_{s}\right) p_{m} T_{s}-h_{s}\left(\frac{p_{s} t_{s}^{2}}{p_{m}}-p_{s} t_{s}^{2}\right)-\tilde{i d}_{s}\left(T_{R}+p_{s} t_{s} \frac{1}{D_{c}}-\frac{1}{p_{m}}\right)-A_{s}\right. \\
& +\left(c_{r}-c_{m}\right) p_{m} T_{s}-h_{m}\left(n p_{m} T_{s} T_{R}-\frac{n^{2}+n-2 r-2}{2} T_{R} D_{R}-\frac{p_{s}^{2} t_{s}^{2}}{2 p_{m}}\right) \\
& -\tilde{i d_{m}}\left(\frac{p_{m} T_{m}-n D_{R}}{D_{c}}\right) \\
& -A_{m}+\left(c_{r 1}-c_{r}\right) p_{m} T_{s}-\frac{h_{r}}{2}\left(\frac{p_{m}^{2} T_{s}^{2}}{D_{c}}-2 n p_{m} T_{s} T_{R}-(2 n+1) T_{R} D_{R}\right) \\
& \left.+\left\{\frac{n c_{r_{1}} D_{c} M^{2}}{2}+\frac{c_{r_{1}}}{2}\left(p_{m} T_{s}-n D_{R}\right)\left(2 M-T^{\prime}\right)\right\} \tilde{I_{r e}}-\tilde{i d}_{r} T_{R}-A_{r}\right] .
\end{aligned}
$$

Table 2 Optimum results for objective functions and other parameters

\begin{tabular}{lcc}
\hline Parameter & Case $\mathbf{1}$ & Case 2 \\
\hline ATP* & $1,039.45$ & $1,108.93$ \\
$p_{S}^{*}$ & 70.49 & $\mathbf{7 9 . 2 3}$ \\
$T$ & 2.85 & 1.59 \\
APS* & 246.51 & 253.56 \\
APM* $^{*}$ & 468.25 & 463.18 \\
APR* $^{*}$ & 321.43 & 390.47 \\
\hline
\end{tabular}


Table 3 Optimum value changes due to parametric changes

\begin{tabular}{|c|c|c|c|c|c|c|c|}
\hline \multirow{2}{*}{$\begin{array}{l}\text { Parameter } \\
\text { name }\end{array}$} & \multirow{2}{*}{$\begin{array}{c}\text { Parametric } \\
\text { value }\end{array}$} & \multicolumn{2}{|c|}{$T^{*}$} & \multicolumn{2}{|c|}{$P_{s}^{*}$} & \multicolumn{2}{|c|}{ ATP* } \\
\hline & & Case 1 & Case 2 & Case 1 & Case 2 & Case 1 & Case 2 \\
\hline \multirow[t]{3}{*}{$c_{S}$} & 1.5 & 1.92 & 1.86 & 79.18 & 78.31 & 10.89 & $1,529.43$ \\
\hline & 2.5 & 1.61 & 1.76 & 46.76 & 78.31 & 10.14 & $1,526.25$ \\
\hline & 3.5 & 1.12 & 1.45 & 18.18 & 78.31 & 10.06 & $1,522.47$ \\
\hline \multirow[t]{3}{*}{$c_{m}$} & 1.5 & 1.82 & 1.82 & 56.14 & 78.31 & 10.56 & $1,528.36$ \\
\hline & 2.5 & 1.75 & 1.65 & 69.76 & 78.31 & 10.46 & $1,525.64$ \\
\hline & 3.5 & 1.10 & 1.33 & 64.15 & 78.31 & 10.15 & $1,520.25$ \\
\hline \multirow[t]{3}{*}{$c_{r}$} & 1.5 & 1.75 & 1.96 & 65.18 & 78.31 & 10.56 & $1,528.19$ \\
\hline & 2.5 & 1.52 & 1.69 & 62.17 & 78.31 & 10.56 & $1,522.58$ \\
\hline & 3.5 & 1.06 & 1.14 & 58.14 & 78.31 & 10.56 & $1,520.43$ \\
\hline \multirow[t]{3}{*}{$h_{s}$} & 1.5 & 1.86 & 1.76 & 69.18 & 78.49 & 10.56 & $1,536.45$ \\
\hline & 2.5 & 1.64 & 1.54 & 64.76 & 78.31 & 10.14 & $1,533.25$ \\
\hline & 3.5 & 1.25 & 1.19 & 60.19 & 78.04 & 10.56 & $1,520.43$ \\
\hline \multirow[t]{3}{*}{$h_{m}$} & 1.5 & 1.09 & 1.76 & 88.76 & 78.74 & 10.56 & $1,530.52$ \\
\hline & 2.5 & 1.21 & 1.52 & 76.78 & 78.54 & 10.18 & $1,525.19$ \\
\hline & 3.5 & 1.13 & 1.01 & 55.45 & 78.17 & 10.56 & $1,523.57$ \\
\hline \multirow[t]{3}{*}{$h_{r}$} & 1.5 & 1.75 & 1.89 & 69.76 & 78.31 & 10.19 & $1,520.43$ \\
\hline & 2.5 & 1.25 & 1.15 & 54.76 & 78.01 & 10.56 & $1,518.29$ \\
\hline & 3.5 & 1.12 & 1.06 & 48.16 & 78.00 & 10.04 & $1,518.21$ \\
\hline
\end{tabular}

\section{The equivalent crisp model}

Using Lemma 1 and applying Theorem 2, the expected total average profit is given by the following:

- For Case $1\left(M \leq T^{\prime} \leq T_{R}\right)$

$$
\begin{aligned}
E\left[\mathrm{AT} \mathrm{T}_{1}\right]= & \frac{D_{c}}{p_{m} T_{s}+D_{R}}\left[0\left(c_{m}-c_{s}\right) p_{m} T_{s}-h_{s}\left(\frac{p_{s} t_{s}^{2}}{p_{m}}-p_{s} t_{s}^{2}\right)\right. \\
& -E\left[\tilde{i}_{s}\right]\left(T_{R}+p_{s} t_{s}\left(\frac{1}{D_{c}}-\frac{1}{p_{m}}\right)\right) \\
& -A_{s}+\left(c_{r}-c_{m}\right) p_{m} T_{s}-h_{m}\left(n p_{m} T_{s} T_{R}-\frac{n^{2}+n-2 r-2}{2} T_{R} D_{R}-\frac{p_{s}^{2} t_{s}^{2}}{2 p_{m}}\right) \\
& -A_{m}+\left(c_{r_{1}}-c_{r}\right) p_{m} T_{s}-\frac{h_{r}}{2}\left(\frac{p_{m}^{2} T_{s}^{2}}{D_{c}}-2 n p_{m} T_{s} T_{R}-(2 n+1) T_{R} D_{R}\right) \\
& \left.-E\left[\tilde{i}_{m}\right]\left(\frac{p_{m} T_{m}-n D_{R}}{D_{c}}\right)+\frac{(n+1) c_{r_{1}} E\left[\tilde{I}_{r e}\right] D_{c} M^{2}}{2}-E\left[\tilde{i}_{r}\right] T_{R}-A_{r}\right] .
\end{aligned}
$$

- For Case $2\left(T^{\prime} \leq M \leq T_{R}\right)$

Table 4 Input data of different zigzag parameters for Case 1 and Case 2

\begin{tabular}{lcccc}
\hline Parameters in uncertain environments & $\tilde{\mathbf{i d}}_{\boldsymbol{s}}$ & $\tilde{\mathbf{i d}}_{\boldsymbol{m}}$ & $\tilde{\mathbf{i d}}_{\boldsymbol{r}}$ & $\tilde{\boldsymbol{i}}_{\boldsymbol{e}}$ \\
\hline Case 1 & $L(0.8,1.2,1.4)$ & $L(1.5,2.0,2.5)$ & $L(1.4,2,2.3)$ & $L(0.04,0.06,0.08)$ \\
Case 2 & $L(1.4,1.8,2.4)$ & $L(2,2.3,2.9)$ & $L(1.4,2.1,2.5)$ & $L(0.06,0.08,0.1)$ \\
\hline
\end{tabular}


Table 5 Optimal values of objective and decision variables

\begin{tabular}{lcc}
\hline Parameter & Case $\mathbf{1}$ & Case 2 \\
\hline ATP* $^{*}$ & $1,056.43$ & $1,520.43$ \\
$p_{s}^{*}$ & 69.76 & 78.31 \\
$T$ & 1.75 & 1.76 \\
APS* $^{*}$ & 248.71 & 276.76 \\
APM* $^{*}$ & 463.43 & 467.35 \\
APR* $^{*}$ & 324.43 & 393.73 \\
\hline
\end{tabular}

$$
\begin{aligned}
E\left[\tilde{\mathrm{AT}}_{2}\right]= & \frac{D_{c}}{p_{m} T_{s}+D_{R}}\left[\left(c_{m}-c_{s}\right) p_{m} T_{s}-h_{s}\left(\frac{p_{s} t_{s}^{2}}{p_{m}}-p_{s} t_{s}^{2}\right)-E\left[\tilde{i d_{s}}\right]\left(T_{R}+p_{s} t_{s} \frac{1}{D_{c}}-\frac{1}{p_{m}}\right)-A_{s}\right. \\
& +\left(c_{r}-c_{m}\right) p_{m} T_{s}-h_{m}\left(n p_{m} T_{s} T_{R}-\frac{n^{2}+n-2 r-2}{2} T_{R} D_{R}-\frac{p_{s}^{2} t_{s}^{2}}{2 p_{m}}\right) \\
& -E\left[\tilde{i d_{m}}\right]\left(\frac{p_{m} T_{m}-n D_{R}}{D_{c}}\right)-A_{m}+\left(c_{r 1}-c_{r}\right) p_{m} T_{s} \\
& -\frac{h_{r}}{2}\left(\frac{p_{m}^{2} T_{s}^{2}}{D_{c}}-2 n p_{m} T_{s} T_{R}-(2 n+1) T_{R} D_{R}\right) \\
& \left.+\left\{\frac{n c_{r_{1}} D_{c} M^{2}}{2}+\frac{c_{r_{1}}}{2}\left(p_{m} T_{s}-n D_{R}\right)\left(2 M-T^{\prime}\right)\right\} E\left[\tilde{I}_{r e}\right]-E\left[\tilde{i d}_{r}\right] T_{R}-A_{r}\right] .
\end{aligned}
$$

\section{Numerical example}

\section{Crisp environment}

The input data of different parameters for Case 1 and Case 2 are shown in Table 1, and the expected optimum value of the total profit is given in Table 2.

\section{Sensitivity analysis}

The major contribution of the supply chain is mainly in the inclusion of the manufacturer. We consider product reworking of defective items which are reworked just after regular production, with a different holding cost for good and defective items in the three-layer supply chain. An integrated production-inventory model is
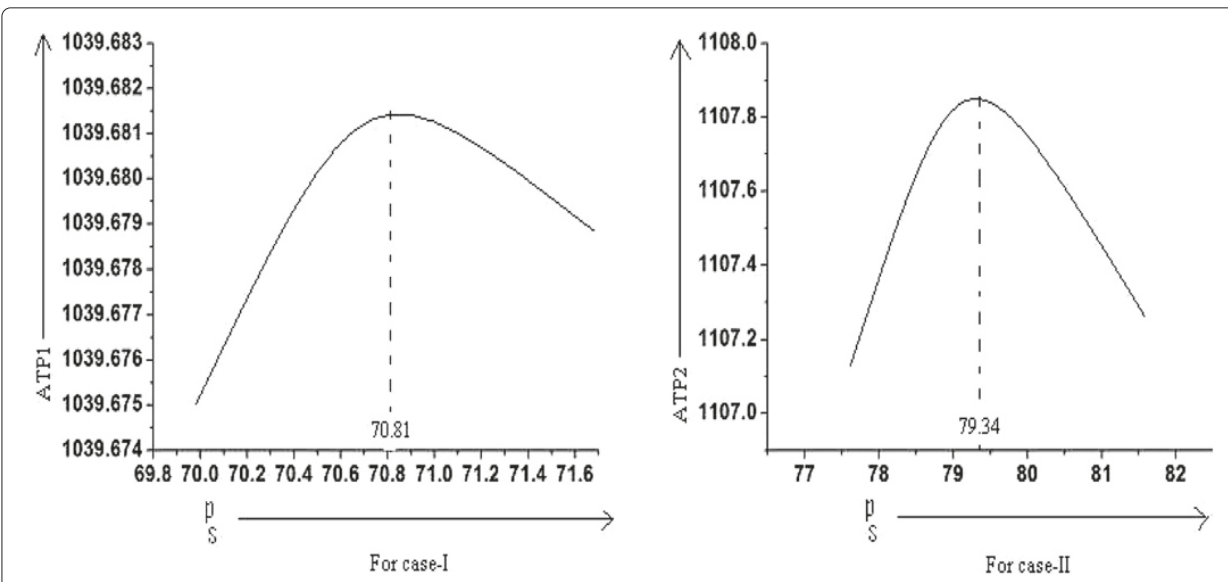

Figure 5 Average profit versus supply rate of suppliers in Case 1 and Case 2. 
presented for the supplier, manufacturer, and retailer supply chain under conditionally permissible delay in payments which has developed in both crisp and uncertain environments (Table 3).

\section{Uncertain environment}

Input data of different crisp parameters for Case 1 and Case 2 are given in Table 1; the remaining uncertain parameters are depicted in Table 4. Optimal values of objective and decision variables are given in Table 5 and graphically represented in Figure 5.

\section{Achievements and conclusion of the model}

In this model, we developed a three-layer production-inventory supply chain model in an uncertain environment. Here, the suppliers are also the manufacturers; they collect the raw material (ore) and produce the raw material of the actual manufacturer. For example, in the petroleum industry, suppliers collect the ore and produce the naphthalene, which is the raw material of the manufacturer. Then manufacturer produces the usable product to sell to the retailer. In this paper, we have developed a production-inventory supply chain model under an uncertain environment. The paper can be extended to imperfect production-inventory system. Deterioration can be allowed for produced items of the retailer and manufacturer. In the case of the retailer, it might be interesting to consider the effect that only a percent of imperfect quality products could be reworked by manufacturers and that other scrap items must be eliminated immediately. In order to show the uncertainties, the present model could be extended, applying stochastic demand and production rate in each member of the supply chain. These are some topics of ongoing and future research, among others.

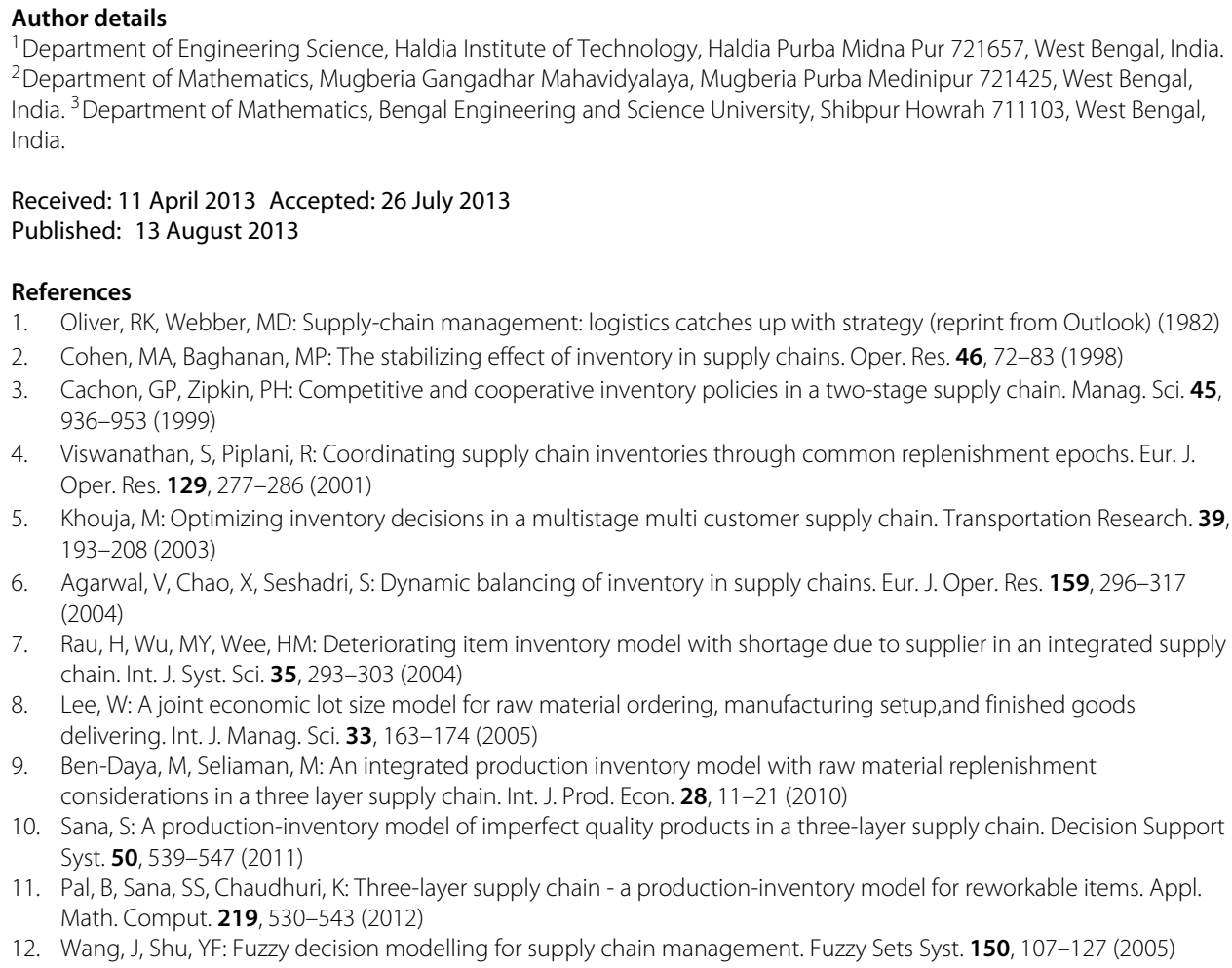

5. Khouja, M: Optimizing inventory decisions in a multistage multi customer supply chain. Transportation Research. $\mathbf{3 9}$ 193-208 (2003)

6. Agarwal, V, Chao, X, Seshadri, S: Dynamic balancing of inventory in supply chains. Eur. J. Oper. Res. 159, 296-317 (2004)

7. $\mathrm{Rau}, \mathrm{H}, \mathrm{Wu}, \mathrm{MY}$, Wee, HM: Deteriorating item inventory model with shortage due to supplier in an integrated supply chain. Int. J. Syst. Sci. 35, 293-303 (2004)

8. Lee, W: A joint economic lot size model for raw material ordering, manufacturing setup,and finished goods delivering. Int. J. Manag. Sci. 33, 163-174 (2005)

9. Ben-Daya, M, Seliaman, M: An integrated production inventory model with raw material replenishment considerations in a three layer supply chain. Int. J. Prod. Econ. 28, 11-21 (2010)

10. Sana, S: A production-inventory model of imperfect quality products in a three-layer supply chain. Decision Support Syst. 50, 539-547 (2011)

11. Pal, B, Sana, SS, Chaudhuri, K: Three-layer supply chain - a production-inventory model for reworkable items. Appl. Math. Comput. 219, 530-543 (2012)

12. Wang, J, Shu, YF: Fuzzy decision modelling for supply chain management. Fuzzy Sets Syst. 150, 107-127 (2005) 
13. Das, B, Maity, K, Maiti, M: A two warehouse supply-chain model under possibility / necessity / credibility measures. Math. Comput. Model. 46, 398-409 (2007)

14. Chen, C, Yuan, T, Lee, W: Multi-criteria fuzzy optimization for locating warehouses and distribution centers in a supply chain network. J. Chin. Inst. Chem. Eng. 38, 393-407 (2007)

15. Peidro, D, Mula, J, Jimenez, M, Botella, MM: A fuzzy linear programming based approach for tactical supply chain planning in an uncertainty environment. Eur. J. Oper. Res. 205, 65-80 (2010)

16. Chu, SJ: Interactive group decision-making using a fuzzy linguistic approach for evaluating the flexibility in a supply chain. Eur. J. Oper. Res. 213, 279-289 (2011)

17. Jana, DK, Maity, K, Das, B, Roy, TK: A fuzzy simulation via contractive mapping genetic algorithm approach to an imprecise production inventory model under volume flexibility. J. Simulation. 7(2), 90-100 (2013)

18. Kristianto, Y, Helo, P, Jiao, J, Sandhu, M: Adaptive fuzzy vendor managed inventory control for mitigating the Bullwhip effect in supply chains. Eur. J. Oper. Res. 216, 346-355 (2012)

19. Liu, B: Uncertainty Theory. 2nd edn. Springer, Berlin (2007)

20. You, C: Some convergence theorems of uncertain sequences. Math. Comput. Model. 49, 482-487 (2009)

21. Liu, B: Fuzzy process, hybrid process and uncertain process. J. Uncertain Syst. 2, 3-16 (2008)

22. Liu, B: Some research problems in uncertainty theory. J. Uncertain Syst. 3, 3-10 (2009)

23. Goyal, SK: Economic order quantity under conditions of permissible delay in payments. J. Oper. Res. Soc. 36, 35-38 (1985)

24. Khanra, S, Ghosh, SK, Chaudhuri, KS: An EOQ model for a deteriorating item with time dependent quadratic demand under permissible delay in payment. Appl. Math. Comput. 218, 1-9 (2011)

25. Maihami, R, Abadi, INK: Joint control of inventory and its pricing for non-instantaneously deteriorating items under permissible delay in payments and partial backlogging. Math. Comput. Model. 55, 1722-1733 (2012)

26. Liu, B: Uncertainty Theory: A Branch of Mathematics for Modeling Human Uncertainty. Springer, Berlin (2010)

doi:10.1186/2195-5468-1-6

Cite this article as: Jana et al:: A three-layer supply chain integrated production-inventory model under permissible delay in payments in uncertain environments. Journal of Uncertainty Analysis and Applications 2013 1:6.

\section{Submit your manuscript to a SpringerOpen ${ }^{\circ}$ journal and benefit from:}

$\checkmark$ Convenient online submission

- Rigorous peer review

- Immediate publication on acceptance

- Open access: articles freely available online

- High visibility within the field

- Retaining the copyright to your article

Submit your next manuscript at $\gg$ springeropen.com 